Bol. Acad. peru. leng. 48. 2009 (157-159)

\title{
"BOMBARDERO", NOVELA DE FRAGMENTOS Y ABREVIATURAS, DE MÚSICA DEL JAZZ Y DEL LABERINTO CONTROLADO
}

\author{
Carlos Eduardo Zavaleta \\ Academia Peruana de la Lengua
}

Fecha de recepción:

$20 / 08 / 2009$

Fecha de aceptación:

$10 / 10 / 2009$

Por suerte, de vez en cuando surgen libros (incluso en nuestra literatura nacional, por lo general silenciosa y algo rutinaria), que representan una aventura experimental, una opinión aparte, una fusión de géneros, que sólo se aclaran por medio de "otra" clase de texto, el cual es a la vez conclusión, ideario, mirador, y ofrece inclusive una música dada, pues las letras no sólo pueden meter ruido, sino producir una música sincopada y de contrapuntos, como la del jazz.

A fines del último año apareció en Lima "Bombardero". Ground zero" (Norma, 2008), de César Gutiérrez, y empezó a ser bienvenida por un crítico muy conocido y por otras voces más débiles y tibias, digo, entusiastas, pero no tanto. O sea que al primer aplauso se sumó la timidez, el "mañana veremos" que puede equivaler asimismo a una duda, si bien no fuese ésa la intención original.

El volumen multifacético llegó a mis manos, y por absoluta coincidencia, se mezcló en el escritorio con algunos volúmenes finalmente 
afines como los que, a propósito de la novela corta "El autómata", de Xavier Abril, estaba yo preparando y que aún no concluyo.

De esos volúmenes puedo citar a los muy conocidos de Cronopios y famas, de Cortázar, o Todo Ubú, riquísimo texto de Alfred Jarry, o las misceláneas Obras escogidas, de Jean Cocteau, mezcla de prosa, teatro, dibujos y travesuras, y todo esto sea dicho al ubicar el polifacético y relampagueante libro del arequipeño César Gutiérrez, en cuya reciente obra hay riesgos, desplantes y desafíos tanto de su paisano Alberto Hidalgo como de los grandes maestros como Joyce.

Con esta introducción sólo deseo acompañar al lector por los numerosos vericuetos y vasos comunicantes del libro, cuyos collages se dan aquí en sucesión y por el llamativo golpeteo del Internet y de sus abreviaturas, para hallar primero un escenario del caos y peligroso desorden del mundo, y de las torres incendiadas de nueva York, para hallar finalmente una posición humanista, optimista y aun humorística, que supera la maraña enrevesada de la estructura y llega, desde el puerto de las desdichas, hasta el reino de la cólera, la sátira y la denuncia contra el actual peligro de guerras atómicas e intercontinentales. Tal denuncia reunifica los fragmentos, las mil facetas de la percepción individual, para ascender a una visión total y macabra, como si fuésemos pasajeros de ese "bombardero" atómico, que no se sabé qué blanco atacará en el mundo, pues su sed de destrucción es su esencia misma.

Sin embargo, en su extraña búsqueda mortal, algo caerá del cielo al planeta tierra, pues el bombardero ha enfilado hacia Santiago de Chuco, hacia la casa museo de Cesitar Vallejo, y todo el edificio literario, lingüístico, poemático y prosístico se tiñe de humor rabelesiano, pinta las honduras ridículas de los Señores de la guerra, y el narrador, habitante y admirador de Nueva York, Londres y París, rinde su homenaje a nuestro pequeño y rústico poblacho, y ahora en el texto se juntan todos los monólogos interiores, aprendidos en Joyce, y en vez de Molly Bloom habla Georgette y despliega su eterna viudez, pero pronto el narrador, que es o desea ser también poeta musical, enmarañado y laberíntico, nos anuncia el final del viaje aéreo, la temida explosión simbólica se produce de hecho y nosotros 
y él y tú "sólo eres polvo blanco en un planeta devastado en un campo minado: dos torres (las de nueva York) que se doblan la gran campana del universo que me dobla y todo a todo color y directo en directo - estamos en el aire", y la obra acaba en este nuevo cambio de géneros y de medios; hemos llegado a la televisión y estamos trasmitiendo.

Así hemos visto el gran caleidoscopio, atracción de niños y grandes, y los temas actualísimos del miedo y de sus bombas, y el escenario cien veces móvil y reemplazable, y el laberinto proseguirá como "unidad" y extraño método de composición, que sólo puede interrumpirse, pero sin concluir.

Bienvenidos sean siempre los experimentos estilísticos y estructurales, porque ellos son el combustible de la literatura artística, no de la banal ni cuotidiana.

\section{Correspondencia:}

Carlos Eduardo Zavaleta

Miembro de Número de la Academia Peruana de la Lengua.

Correo electrónico: academiaperuanadelalengua@yahoo.com 